\title{
La fiebre amarilla en Piura Breves consideraciones sobre su naturaleza
}

\author{
(Conclusion)
}

\author{
POR EL DR. CARLOS ENRIQUE ZAPATA
}

Historia clínica N.07.-P. C. O, natural de Piura, de 8 años de edad, residente en Piura y domiciliada en la calle de Junín $\mathrm{N} .{ }^{\circ} . .$. , en la misma casa donde enfermaron de la misma epidemia, en días anteriores, 3 de sus hermanos.

Cuenta la familia que el día 3 de Agosto, en la noche, se enfermo con calofrío violento, fiebre no muy alta, dolores lumbares generalizados a los miembros inferiores y nauseas.

El día 4 en vista de que no se aliviaba y habiendo aparecido un dolor muy fuerte en el est6mago y v6mitos con estrías sanguinolentas, solicitaron los servicios profesionales del Dr. González, quien denuncí el caso a la Oficina Sanitaria, cuyos medicos constataron el siguiente cuadro:

Aparato digestivo.-Labios secos y resquebrajados,lengua blanca en el centro y roja en los bordes, ligera angina, falta de apecito, dolor expontáneo y provocado en el epigastrio, que se exaspera mucho más en el momento del vómító. Vientre deprimido. V6mitos con estrías sanguinolentas y constipecion bien marcada.

Existe además en el aspecto general una cara congestionada, conjuntivas inyectadas, que hacen pensar, con los síntomas anterformente descritos, en el cuadro que presentan al principio las fiebres eruptivas.

Por el lado del aparato urinario encontramos la orina disminuida, y examinandola se encuentra régular cantidad de albúmina.

Aparato circulatorio.--Pulso muy débil. 112 latidos al minuto.

Sistema ganglionar.- Ganglios cervicales un tanto dolorosos. - Temperatura 38,5

Régimeri. - Hielo y bebidas heladas. Poc. Riviere, inyección de aceite alcanforado y cafeína.-Enemas oleosos y hielo al vientré.

Día 6. - El cuadro permanece más o menos el mismo.-Los vómitos han disminuido en intensidad, lo mismo que el dolor al epigastrio. La temperatura es de 37,5 con 100 pulsaciones. Se nota un ligero tinte ictérico en la esclerb́tica.

Dias 7 y 8 . - El cuadro ha mejorado.- La temperatura es de 37 con 80 pulsacio. nes y los $7 v 6$ mitos casi han desaparecido. La orina se elimina en cantidad normal, pero siempre se encuentran trazas de albamina al examinarla. El tinte sub-lctérico de la : esclerb́tica permanece como el día anterior.

Días 9, 10 y 11 . - Su estado general ha mejorado y su temperatura es la normal.

Historia clinica $N .0^{-} 8$. - J., natural de Plura, de 5 años de edad, mujer, de raza blanca. Ha caído enferma el 5 de Agosto de 1919, con fiebre alta y dolores generalizados, principalmente al eplgastrio y réquis. 
El día 6 se denuncia el caso, consticuyéndose inmediatamente los doctores Hanson y Quiroz, quienes encuentran a la enferma con temperatura alta de 39, 1/a grados. muy decaída. casi soporosa: las conjuntivas están ligeramente inyectadas, el pulso es algo lento. La familia manifiesca que no tiene náuseas ni vómitos. La lengua está saburral, no hay icceria.

Con los dacos anteriormente citados se considera el caso sospechoso y se aisla bajo mosquitero y se recomienda a la familia recoger la orina para hacer un ańlisis.

El día 7 la enferma ha empeorado, está inconsciente, la cemperatura continúa alta, 40 grados, el pulso es pequeño y muy frecuente. Hay ligero tinte sub-ictérico. Ha tenido vómitos negros, muy repetidos. El higado se encuentra doloroso y ligera. mente aumentado de volumen. La orina es casi nula

El día 8 la sicuación es todavía más grave, la enlerma está profundamente ictérica, la orina ha desaparecido por compleco, el pulso es incontable y muy pequeño hay abundances diarreas y la enferma fallece a las l I de la mañana.

Hisloria clínica N.9.-J. M. de 20 años de edad, nacural de Catacaos. soltero, doméstico de la casa de don César Corcez, casa situada en la manzana donde se presentaron los primeros casos de esta epidemia, Reside en Piura hace 4 años. Domicilio calle de La Libercad N. ${ }^{\circ}$...

Principió su enfermedad el 5 de agosto, y cuenta la lamılia que se inicib con calofrío, y fiebre elevada, 39 grados, en el primer momento.

Día 8. - Este día fué el de la denuncia y se le hizo ingresar al Lazareco a las 9 y 30 de la mañana. El estado general no es alarmante. La temperatura es de 39.4 con 96 pulsaciones al minuto; se nota al mismo tiempo por el lado del aparato digestivo. una falta de apetito,un ligero estado nauseoso. además hay angina algo manifiesta. y examinada la orina se encuentra albúmina en gran cantidad El aparato respiracorio en buenas condiciones.

Día 9.-Angina más dolorosa que el día anterior. - Hay náuseas y vormicos alimenticios. Dolor al epigastrio y tinte ictérico bien pronunciado. Por el lado del aparato respiratorio se encuentra una disnea algo pronunciada. En cuanto al pulso este llega a 110 pulsaciones, en la mañana y a 124 en la tarde, haciéndose cada vez más débil.

Aparalo urinario.- La orina disminuye en cantidad notablemente; analizada encontramos gran cantidad albúmina, mucho más que el día anterior.

Sistema nervioso.- Exitación, el individuo no puede estar un momento tranquilo, se levanta grita y dice en medio de sus gritos que el dolor de cabeza no lo puede soportar, por su incensidad.

La temperatura llega en este día a 38,8 en la mañana y a 39,2 en la tarde.

Regimen.-Cataplasmas calientes al cuello y gargarismos para combatir la angina. Hielo al epigastrio por el estado nauseoso y a la cabeza. Inyecciones estimulantes, aceite alcanforado, etc.

Día 10.-Aparece por primera vez el vómito negro con bastante incensidad, icteria bien marcada y una gingivorragia. El pulso late a 144 pulsaciones y es fili. forme. El dolor al epigastrio se hace casi insoportable y la disnea se hace más intensa. Aparato urinario.-La orina ha desaparecido completamente desde la ma.. drugada y se inicia el coma urérnico.

Día 11 .-La sintomatología del día anterior es cada vez más marcada, a pesar de tratamiento estimulante enérgico a que se encuentra sometido.

Día 12.-El enfermo muere a las 2 p.m. de este día en medio de un coma uremico bien marcado.

Después de la muerte el cadáver ha tomado un tinte amarillo intenso.

Historia clínica N. 10.-C. V. natural de lima, de 7 años de edad, con un año de residencia en Piura, domiciliado en la calle de la Libertad $\mathrm{N}$. . . ... casa donde habian enfermado con la misma enifermedad, en el espacio de 5 días, 7 sujetos. Esce niño se enfermb el 7 de Agosto con calofrío violento, fiebre alta de 40 grados centígrados, cefalalgia intensa, dolores en la region lumbar que se extienden a los miembros inferiores, inyección conjuntival y ligera angina. Por el lado del aparato urinario se nota que la orina esta ligeramente albuminosa.

Trasladado al hospital el dla 9 encontramos lo que sigue:

El enfermo se encuentra agitado, con una temperatura de 40,6, la cara esta roja. las conjuntivas están inyectadas. La lengua está recubierta en su parte media de una capa más o menos espesa, mientras que jos bordes estan rojos.-El dolor al epi- 
gastrio se exaspera con los vómicos que en este día ya se hacen frecuentes. La anglna persiste en la misma forma que el día anterior y además, hay marcaoa constipación. La celalalgia y la raquialgia son marcadas, tanto como el primer día. Examinada nuevamente la orina, se encuentra albúmina en gran cantidad.

Se prescribe como régimen, hielo, fricciones alcoholizadas, aspirina y un enema de agua hervida.

Día 10.-El enfermo está en las mismas condiciones, solo se nota un ligero tinte sub-ictérico en la piel.

Día 11.-La temperatura llega a 38,2 por la tarde con 90 pulsaciones. Hay v6mitos biliosos y la angina es más pronunciada. El tince sub-ictérico de la piel es el mismo. Los dolores de cabeza y lumbares van disminuyendo

Se le administra bebidas heladas y hielo al vientre y a la cabeza.

Día 12 y 13.-El enfermo ha mejorado en su escado general, los símtomas gástricos casi han desaparecido, solo persiste una pequeña cefalalgia y temperatura de 37,8 con 80 pulsaciones.

Días 13, 15 y 16.- Se inicia una notable mejoría en el enfermo, la temperatura ha llegado a la normal, persiste el tinte ictérico de que he hablado anteriormence, que es más pronunciado que en los primeros días y el pulso late 60 veces por minuto. Esta lenticud del pulso se nota por varios días, es decir en plena convalescencia, hasta que poco a poco va volviendo a la normal.

Historia clínica N. 11 - - J. P. natural del Arenal, provincia de Paita, de 19 años de edad, residente en Piura hace 3 años y domiciliado en la calle del Cuzco N. ${ }^{\circ}$. . Se enfermb el 10 con calofrío violento. fiebre intensa de 40 grados, desde el primer momento, náuseas y vómitos, inyección conjuntival, pulso 120 al minuto, examinada la orina se encuentra gran cantidad de albúmina.

Dia /1. - Lengua saburral y seca, labios secos y resquebrajados, estado nauseoso. angina, anorexia, fuerte dolor al epigástrio y a la región lumbar, hiperrofla del hígado y constipación.

Aparato respiratorio.-Disnea.

Aparato circulatorio.- Pulso débil, 112 latidos al minuto.

Aparato urinario.-Albuminuria, oliguria, concentración de la orina, sedimento abundante.

Sistema nervioso.-Cefalalgia y exitación.

Sistema ganglionar.-Normal.

Calorificación.- Esta es de 38 grados en la mañana y 39,2 en la tarde.

Piel.-Icteria.

Organos de sentidos.-Inyección conjuntival, icteria en la eclerbtica.

Estado general. -Malo.

Régimen.-Enemas oleosos y con agua oxigenada.-Hielo al vientre, a la cabeza y bebidas heladas, inyeccibn de aceite alcanforado, esparteína y digitalina.

Día 13.-Lengua seca y negra.-Encías sangrantes; angina; náuseas, v6micos sanguinolentos; anorexia; dolor al epigastrio, que exaspera al enfermo, mucho más intenso que en el día ancerior; como consecuencia de los enemas puestos el día anterior ha cesado la consipacion, pero en cambio se han presentado con mucha frecuencia, diarreas negras, que no son otra cosa sino melenas.

Aparato respiratorio. - Aparece una epixtasis muy abundante, que no se detiene expontáneamente, sino después de haber empleado medios enérgicos, pero para reproducirse más tarde.-Existe disnea algo pronunciada y tos seca.

Aparato urinario. - Hay una marcada disminución del volumen en la orina, pues apenas se ha recogido $150 \mathrm{cc}$. en las últimas 24 horas, que examinada por medio del calor, da gran cantidad de albúmina.

Aparato circulatorio.-Pulso muy débil, 80 latidos al minuto en la mañana y 70 en la tarde.

Sistema nervioso.-Cefalalgia muy intensa que desespera al enfermo.

Calorificación. - 39 grados en la mañana y 38,8 en la tarde.

Existe además marcada exitación y una pronunciada icteria.

Régimen; estimulante.

Días 13 y 14 .- La orina ha llegado a suprimirse completamente, es decir la anuria ha llegado y un ataque de coma urémico se inicia con todo su cortejo de síntomas, que son los más penosos. 
Día 15.--El coma urémico continúa su labor de destrucción y a él se vienen a sumar otros sintomas rales como: una epixtasis, melenas abundantes, y una gingivorragia que termina con el enfermo.

Poco tiempo después de la muerte el cadáver tomó un color amarillo intenso, amarillo de azufre.

Hisloria clínica $\mathrm{N} \cdot 12$-F. L. indigena de Ayabaca, procedente de esta ciudad. donde ha residido 4 años. Tiene 15 años de edad y habiia en la calle de Ayacucho

Se enfermó el 17 de Agosio por la tarde, pero solo se denunció, por el Dr. Gonzales, el 19. Príncipió la enfermedad con un malestar y un fuerte calofrío en la tarde del 17 seguido de fiebre alta. esta fiebre dur6 los días 18 y 19 , en que viendo que el estado permanecía el mismo, a lo que se agregaba las náuseas y un dolor agudo al nivel del epigástrio.llamaron al Dr. Gonzales quien pudo constacar un vómito negro. sanguinolento.

Consticuídos los miembros de la Oficina Sanitaria, nos encontramos con una una menor demacrada, con tinte ictérico en las conjuntivas y melenas. Los labios se encontraban secos y resquebrajados, las encías secas y sangrantes; lengua de loro. náuseas, dolor en el epigástrio, vómicos negros, temperatura 38, pulso filiforme y muy frecuente, disnea y oliguria.

Fué llevada al Lazareto el 20 de Agosto, en donde la sintomatología permanece idéntica hasta la tarde,en que la temperatura baja a la normal y el pulso se hace más frecuente, los vómitos negros son cada vez más intensos y la orina desaparece por completo. Practicado el examen de la orina. eliminada el día anterior. se constaca solo una abundante cantidad de albúmina, no se encuentra hemoglobina

Día 21.-Los síntomas siguen en el mismo estado y la enferma muere a las 9 de la mañana.

Historia clínica N. 13--Z. S. natural de Morropón, de 20 años de edad, de raza mestiza, reside en Piura hace 10 años, en la calle de Arequipa N.070, en la misma casa donde enfermó su hermano que falleci6, de la misma enfermedad.

Esta niña cae enferma el 20 de Agosto y es denunciada por el Dr. Vega, el 23 Tiene buenos antecedences hereditarios y personales. Los sintomas iniciales corresponden por su naturaleza e intensidad al período de la invación de la actual epidemia reinante: la fiebre amarilla.

En éfecto nos relata la familia que la enfermedad principib con calofrío, raquialgia, cefalalgia, inyección conjuntival, dolor al epigastrio, ecc. síntomas estos que fueron constacados por nosotros y que practicado el diagnóstico diferencial de las entidades mórbidas de manifestaciones comunes, llegamos a concluir aceptando el caso como de fiebre amarilla, forma inflamatoria de índole benigna.

La temp. en este día es de 39 grados, tanto en la mañana como en la tarde. En los días sucesivos es más característico el cuadro clínico, hay una pequeña cantidad de albúmina en la orina, un ligero tinte sub-ictérico de la piel y conjuntivas y un estado e mésico pasajero

La curva térmica desciende al cuarto día por crisis, hasta por debajo de la normal.

Al exámen del aparato respiratorio no enconcramos nada de anormal.

En el aparato circulatorio se aprecia muy ligera astenia cardiaca, hay bradicardia.

En el aparato digestivo, existe un pequeño aumento del lobulo izquierdo del hígado y una dolorabilidad en el hueco epigástrico.

Días después la enferma entra en franca convalescencia, después de 6 días de enfermedad.

Historia clínica N. 14.-R. E. M. de 18 años de edad, nacural de Ayabaca, soltera, de raza blanca, residente en Castilla, en el local del Hospital de Belén.

Cae enferma en la noche del 25 de Agosto, con calofrios, vómitos y raquialgia. Al ser examinada por nosocros encontramos lo siguiente: fiebre 39.5 ; dolor muy marcado en el epigastrio y cefalalgla muy incensa; examinada la orina encontramos una fuerte cantidad de albúmina. La inyección conjuntival es muy marcada.

Los primeros días de la enfermedad evolucionan con los mismos síntomas.pero un tanto más acentuados; así el tinte de la conjuntiva se hace más acentuado, la curva términa sigue elevada entre 38,5 y 39 ; los vómitos son pertinaces, alimenticios primero y biliosos después. Hay insomnio y postración general.

A partir del quinto día de la enfermedad, la fiebre comienza a descender por lisis 37,$8 ; 37$ y 36,2 a la vez que todos los síntomas enunciados descienden en Inten- 
sidad. La cantidad de orina eliminada aumenta en cantidad, se presentan plgmentos biliares y la reacción de foida que era se torna francamente alcalina.

Con relación a este dato ́́ltimo, debemos confesar que la alcalinidad de la orina de un amarílico, habla en favor de su mejoría, pues esto lo hemos anotado en muchos de nuestros enfermos, pues aún cuando la reacción normal de la orina es ácida la persistencia de esta en el tifus icteroides es un signo desfavorable para el paciente. Nuestra enferma entra en franca convalescencia después de 10 días de enfermedad.

Hitsoria clínica N.० 15.-M. F. de 22 años de edad, natural de Piura, de raza india, procedente de la misma ciudad, domiciliado en la calle de Loreto N. $\circ$...

Este paciente fué ocultado y tratado clandestinamente en su domicilio hasta el sexto día de la enfermedad. Denunciado por el Dr. Gonzales el día 13. de Setiembre observamos una tempertura de 38,5 con 100 pulsaciones al minuto, respiración de Cheines-Stokes.-Escado general malo. Observamos también la presencia de una epíxtasis. El análisis de orina revela fuerte cantidad de albúmina, y tanto la piel como las conjuntivas presentan tinte ictérico bien marcado.

Por los datos que tenemos del curso de la enfermedad, desde que se inici6 hasta esta fecha, nos imponemos que el día 7 estando en condiciones de aparente salud diose un baño en la tarde, sintiendo en la noche un fuerte calofrío, seguido de fiebre alta, con dolores en la cintura y cabeza; que durante tres días la fiebre, continu6 en el mismo estado, para tener una remisión después, que fué seguida de una nueva elevación térmica hasta el día 13 fecha de nuestro examen. El síntoma vómito tampoco ha faltado, pues aunque la familia niega la frecuencia de ellos, confiesa su existencia en los primeros días, de carácter alimenticio.

Examen de los órganos.-Higado. El 16 bulo izquierdo algo aumentado de volumen; hueco epigástrico doloroso a la presión y algo deprimido.

Bazo.-Examinada la región esplénica la encontramos normal.

Aparato respiratorio. - Los pulmones $y_{0}$ bronquios no ofrecen nada de patol6gico, que explique el estado de gravedad del enfermo.

Aparato urinario.- Existencia de una nefritis infecciosa aguda, como lo revela el coma urémico en que se encuentra.

El paciente fallece en la madrugada del día siguiente, ofreciendo su cadáver un tinte bien marcado de azafrán.

Hisloria clínica N.0.16.-I. A., de 6 años de edad, de raza mestiza, procede de la misma ciudad, calle de Junín, barrios del norte. infectados. Buenos antecedentes hereditarios y personales.

Se enferma el sábado 13 de Setiembre con calofrío intenso seguido de fiebre alta, cefalalgia y dolores en la región lumbar, que se extienden hasta los miembros inferiores. - Este niño permanece oculto en su domicilio hasta el sábado 18 , fecha en la que se solicita los servicios profesionales del Dr. Gonzales, quien hace la denuncia.

No existen datos concretos sobre la curva térmica, ni sobre la marcha de la enfermedad. - Las referencias que se nos suministran son en el sentido de haber estado febril durante los días de la enfermedad, haber habido algunos vormitos alimenticios y fuerte dolor de cabeza.

Al examen hecho por sl suscrito se constaca: hipotermia, falsos pasos en el corazbn y estado general de pre-agonía.-El análisis de orina revela la presencia de fuerte cantidad de albúmina; el tinte ictérico de la piel y de las conjuntivas es bastante manifiesto, tinte que se pronuncia aún $m a_{s}$, horas después de la muerte; que tuvo lugar el 19 a las 4. a.m.

Encontrándose en esta ciudad el general Gorgas, célebre médico americano, a quien el gobierno le había encargado hiciera especialmente a este departamento una visita con el objeto de que viera de cerca las condiciones sanitarias de él y habiendo solo encontrado un caso de fiebre amarilla, en Sullana, en una señora de Gomez, ceso que dijo ser típico de fiebre amarilla, se orden6 por los médicos sanitarios de esta ciudad se hiciera la autopsia de este menor, que se hizo en presencia de dicho general y su comitiva, entre los que se encontraban algunos médicos ecuatorianos de conocida reputacion.

Estos señores medicos observaron con los de la localidad, lo que a continuacion expongo.

Aspecto exterior del cadáver.-El color amarillo de la piel se encuentra bastante pronunciadó. 


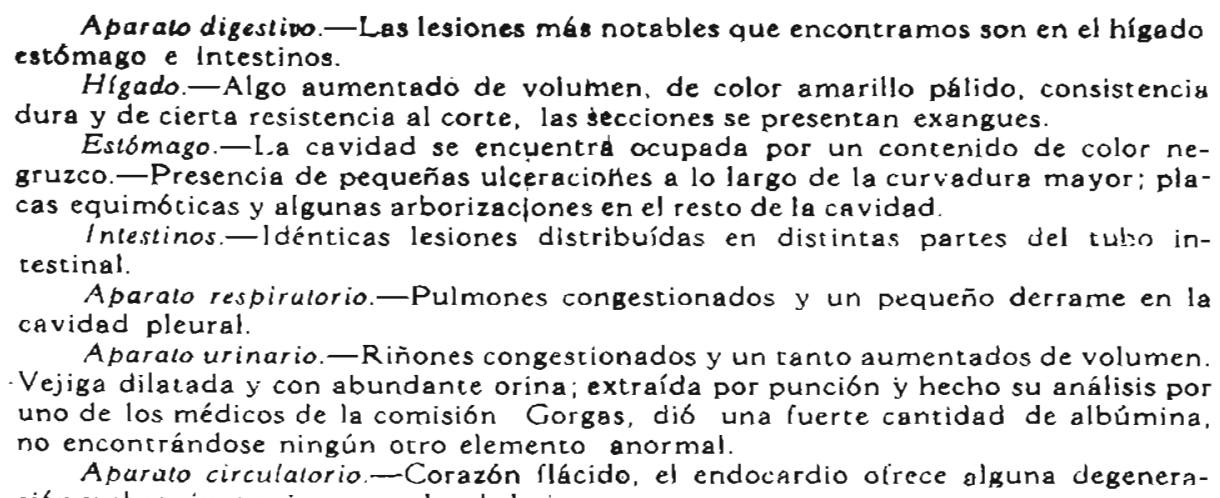
ción y el conjunto tiene un color de hoja muerca.

Hisioria clínica N.017.-C. E. Q., natural de Piura de raza mestiza, procedente de Piura, constitucion luerte. Buenos antecedentes hereditarios y personales. Domicilio en calle de Junín $s-n^{\wedge}$. foco de algunos casos presentados últimamete de la epidemia reinante.

Enferma bruscamente en la mañana del 17 de seriembre, con calofrío intenso. cefalalgia, dolores lumbares, fiebre y postración general.

El día 18 se nos dice que paso en las mismas condiciones, solo que el estado emético se hace manifiesto, pues habían náuseas y algunos v6mitos biliosos.

El día 19 son solicitados los servicios profesionales del Dr. Guzmán, quien encuentra 40 grados de temperatura, vómitos de contenido negruzco, dolores al epigastrio, epíxtasis y fuerte cantidad de albúmina en la orina.'

El día 20 la temperacura es de 38 grados, pulso 120 al minuro. los vómitos han disminuído, así como la exicitabilidad y los dolores agudos de la regiones lumbar y epigástrica.

El día 21 desciende la temperacura a $37,1 / 2$, el enfermo responde con lucidez a as preguntas que se le hacen, la çefalalgia persiste, la albúmina sigue encontrándose; se nota también un ligero tinte sub-ictérico en la conjuntiva y cierta contractura de los músculos de la nuca, asi como la actitud general del cuerpo en gacillo. El enfermo se queja a intervalos de fuerte dolor de cabeza.

El día 23 la temperatura es de 37,8 , el estado general es mejor.

Constituidos el Dr. Gastiaburá y el Dr. Quiroz, se coma sangre dei enfermo por punción venosa, sangrc que fué inoculada a un cui llevado para el efecto.

1 Día 24.- Se acentúa la mejoría, desaparecen en gran parte las manifestaciones de meningismo; persiste la albúmina y el tinte sub-ictérico de la conjuntiva.

Durante los días 25,26 y 27 mejora notablemente el enfermo y la albumina digminuye gradualmente. Poco después sale curado.

Examen bacteriologico.- El jueves 2 de Octubre, el Dr. Gastiaburú, dé a conocer por medio de una conferencia en el lacal de la Prefectura los resultados de sus trabajos experimentales y bacteriologicos de la sangre de este enfermo.-La leptospira icteroides, ha sido hallada en los cultivos y visca al examen del ultramiscroscopio.-El germen es constatado y visto por todos los asistentes. - La leptospira de Noguchi, germen especifico de la fiebre amarilla según este sabio, fué bien observado.

Ténica seguida.-Tomada la sangre del enfermo fué inoculada a un cul. Este enfermb con fiebre 4 dlas después; sacrificado se saca sangre del corazón que se siembra en el medio de Noguchi y del cual se extrajo para los exámenes ultramicroscb. plcos.

\section{ANATOMÍA PATOLÓGICA}

Aún cuando las lesiones anatomopatológicas, que en seguida vamos a describir, no pueden ser consideradas como patonogmónicas del tifus amarillo, es indudable que esas lesiones, unidas a los sínto-

Anl. 4 
mas que hemos descrito nás arriba, agrupados en el mismo sujeto y relacionados los unos con los otros, imprimen a la enfermedad una fisonomía especial, un sello absolutamente personal, que en la mayoría de los casos, impone el diagnóstico.

Aspecto exterior.-Icteria.-- En todos los cadáveres amarílicos la hemos visto perfectamente marcada, mucho más que durante la vida, y sobre este tinte general de los tegumentos marcadamente amarillo, se observan placas brunas, equimóticas, claramente visibles en el cuello, párpados y espalda. Hemos visto también que las cavidades nasal y bucal, dejan salir una materia negra muy semejante al vómito que tuvieron durante la vida. La región perineal está frecuentemente manchada con melena.

Aparato digestivo:- Estómago fuertemente congestionado y lleno de un líquido negruzco, que tiene la apariencia del café molido, semejante al vómito y deyecciones del enfermo; nótase además que la serosa se halla libre de lesiones, pero la mucosa está intensamente lesionada con erociones o pequeñas ulceraciones más - menos numerosas y más o menos extensas, que se encuentran á lo largo de la grande y pequeña curvadura y cerca de los orificios pilórico y cardiaco, etc. Estas lesiones explican, bajo el punto de vista clínico, y en razón de la importancia de la profundidad del terreno atacado, no sólo el vómito negro sino también la epigastralgia intensísima.

Intestino delgado.-Participa de las mismas lesiones del estómago, sobre todo en sus primeras porciones; estas explican los fuertes dolores que sienten los enfermos en la región umbilical.

Hígado- - A primera vista se ve que este órgano está alterado profundamente en todos sus elementos, alteración que trae como consecuencia clínica, la insuficiencia hepática aguda, en razón de que el hígado desempeña funciones numerosas y delicadas, "y es en este órgano donde se encontrará en parte la explicación de los síndromés tóxicos, hemorragias múltiples, desórdenes nerviosos y gástricos, etc. que son la consecuencia oridinaria de esta insuficiencià." (Clarac' y. Simond, Fiebre Jaune, Paris, 1917).

Por lo demás: hemos: visto a este órgano casi siempre aumentado de volumen, con un color amarillento, en muchos casos amárillo intenso, lo que indica en estos casos mayor estado de degeneración, en la cual el parênquima está reblandecido y se desgarra fácilmente cuando se toma con la pinza. Además hemos constatado péqueñas zonas rojizas de consistencia dura, que al corte se èncuentran exangües. 
Bazo.- Su estado es normal en casi todos los casos y esta constatación es prueba definitiva e inobjetable contra la hipótesis de Paludismo, que a propósito de esta epidemia se suscitó en Piura por dos facultativos, los doctores Cueva y ValCarcel. Y para mayor fuerza de lo que digo más arriba, copio en seguida lo que al respecto dice Dutroulau, que resume la opinión de los escritores más autorizados: "su estado es normal en casi todos los casos y su examen ha resuelto uno de los caracteres diferenciales los más incontestables, de la fiebre amarilla y la fiebre palúdica. En efecto, la hipertrofia y el reblandecimiento del bazo son caracteres casi constantes de la intoxicación palúdica, mientras que su integridad en la fiebre amarilla excluye su naturaleza palustre".

Aparato génito-urinario.-Riñones.-Aumentados de volúmeny con signos manifiestos de degeneración. Su color es amarillo rojizo. Su consistencia normal está disminuida y se encuentran, casi siempre pequeñas zonas reblandecidas y friables. Estas lesiones exptican clínicamente, la disminución de las orinas, "que se ha ce más grave si va hasta la suspensión completa o anuria, de pronóstico casi siempre fatal.

Vejiga.-Unas veces vacía y otras conteniendo pequeña cantidad de orina.

Aparato circulatorio - Corazón - Grasoso y con trazas de degeneración.

Pericardio--Conteniendo pequeña cantidad de líquido seroso.

Aparato respiratorio - Putmones. - Congestionados mucho más en la base, particularmentè en el liado derecho.

Pleuras.-Conteniendo abundante derrame sanguíneo, particularmente en la cavidad derecha.

Esto es todo lo que se refiere a las lésiones macroscópicas.

En cuanto a las lesiones histológicas, estas no se han podido hacer; primeramente; por la falta de facilidades y de los inedios ind ispensables para realizarlas, y segundo, parque aquellos encargádos de hacerlas, es decir, aquellos que llevaron desde aquí los elementos necesarios, no encontraron sujetos en quienes actuar, porque llegaron muy tarde, ya cuando la epidemia haba dechinado por completo en la ciudad de Piura y sus alrededores, debido a las medidas de profilaxia que tomó la Oficina Sanitaria.

\section{Algunas CONSIDERACIONES DIAGNósticas}

Hemos' visto en el estudio clínico y hemos dicho, al hablar de anatomía patologica, que el tifus amarillo no tiene-lesiones que pue- 
dan considerarse como patonogmónicas, pero que estas lesiones unidas a los síntcmas, "agrupados en un mismo sujeto, relacionados los unos con los otros, con matices más o menos acusados, imprimen a la enfermedad una fisonomía especial, un sello absolutamente personal que, en la mayoría de los casos, no deja el menor lugar a duda e impone el diagnóstico

En Piura, ante los primeros casos importados, presentados en 4 y 5 de Junio, la hipótesis de fiek re amarilla se mantuvo en reserva, en vista de fálta de datos sobre su importación. Pero bien pronto el cuadro clínico se aclaró con la necropsia de la menor Ojeda, practicada el 27 de Junio, y la determinación de la vía que siguió la enfermedad al penetrar; desde entonces cesaron todas las indecisiones y se levantaron todas las dudas.

Es verdad que es miuy difícil al principio de una epidemia estaklecer un diegróstico a firme, sotre todo tratandose de fietre amarilla, muy ccnfurcitile con algunas afecciones febriles de las zcnas trcpicales, pcro era necesario hacerlo y precoz, en razón del peligro que preserta un ámarílico en los 3 o 4 primeros dís de la enfermedad.

La rifćctcsis de fietre emarilla se aceptó pues, en vista de haterse $\epsilon$ statlecicio en forma concluyente que ella fué importada de Guayaquil, y témlién for el descultribiento, hecho por el Dr. Gastiablru en el enfermo Carlos Eduardo Quinde, de la Leplospira itteroide de N'ogcchi.

Hemos dicko que la fiekre ámarilla se confunde con algunas afeccicnes fetriles de las zonas trcpicales y con algunas otras que reinan $\epsilon \mathrm{n}$ tcdes los climas. Frocuraremos estudiar, aunque sea a grandes rasgcs, las diferencias que hay entre éstas y la fiebre amarilla.

Dengue.— - La brusquedad del principio, la raquialgia y la epigestralgia intensas, imprimen a estas dos afecciones cierta coruridad; pero la icteria, los vómitos negros, la altuminuria prorunciada, síntcmas propios de la fiebre amarilla, no se encuentran jamás en el dengue. De otro lado la erupción constante en esta última afección no presenta los mismos caracteres cuando ella existe en la fiebre amarilla». (Dengue, doctor H. Reboul). Con respecto a la erupción diremos que nosotros no la hemos constatado en ninguno de los 112 enfermos observados en Piura, de manera que suponemos se presente en uno que otro caso.

Por otra parte "la distribucićn geográfica de estas dos afecciones puede, en ciertos casos, constituír un elemento de diagnóstico, porque si el dengue se vé en todas las localidades donde la fiebre 
amarilla es endémica, la recíproca no es verdadera". (REBOuL, loc. citada).

Fiebre biliosa hemoglobinúrica.-Se ha insistido mucho sobre el diágnóstico diferencial de la fiebre amarilla y de la fiebre biliosa hemoglobinúrica. La fiebre amarilla según Gouzien no tiene la misma distritución geográfica que la fiebre biliosa hemoglobinúrica: ella es desconocida en algunos sitios donde se vé esta última (Grecia, Madagascar, etc.). La fiebre amarilla es una afección esencialmente transmisible, "un primer ataque confiere inmunidad y su período de incubación nunca pasa de 7 días, mientras que la fiebre biliosa hemoglobinúrica no se comunica de ningún modo de un sujeto a otro, pero recidiva con una gran facilidad y puede estallar muy largo tiempo después de haber salido del foco de origen". (PAUL GouzIEN, Fiebre biliosa hemoglobinúrica).

Nosotros que hemos observado muchos casos de la epidemia existente en el departamento de Piura, no hemos podido constatar ninguna recidiva, lo que hatla en favor de la fiebre amarilla.

Además, en la fiebre tiliosa hemoglobinúrica, la icteria es muy precoz, en lugar de ser tardía, como ha pasado en la epidemia de Piura, que casi siempre se ha presentado en el tercero o cuarto día de la enfermedad, algunas veces antes, cuando los casos han sido muy graves, pero nunca desde el primer momento, y así lo acreditan nuestras historias clínicas.

«En fin y sobre todo, la coloración roja inicial de las orinas es suficiente para levantar todas las dudas, porque si la orina de los amarílicos es fuertemente albuminosa, ella conserva su tinte normal y no contiene hemoglobina*. (Gouzien, loc. citada). En ninguno de nuestros enfermos la orina ha tenido un color anormal, ellas se han presentado límpidas, sin ningún color característico.

"Cuando apesar de todo esto, las dudas subsisten, sea porque los síntomas no han sido perfectamente claros, sea porque el médico ha llegado después de la muerte, la autopsia permite fijar el diagnóstico". (Clarac y Simond, diagnóstico de la fiebre amarilla). En los sujetos que mueren de fiebre biliosa hemoglobinúrica el bazo se encuentra aumentado de volúmen y reblandecido, lo que no pasa en los muertos por fiebre amarilla, cuyo bazo se encuentra normal; asi lo atestiguan nuestras autopsias Nos. 3, 5 y 16.

Paludismo.--"La existencia, en las mismas localidades, de fiebres endémicas de origen palúdico trae la dificultad en el diag- 
nóstico de la fiebre amarillax. (Dutroulau). En efecto, los variados aspectos bajos los cuales se presenta el paludismo y la similitud en algunos de sus síntomas con la fiebre amarilla, fueron el punto de partida, en la ciudad de Piura, para sentar una doctrina tan errónea como funesta, consistente en presentar la epidemia de aquella ciudad como una fiebre remitente biliosa, pero esta docdoctrina tuvo que desaparecer ante la sana apreciación de los hechos. Asi, en la fiebre remitente biliosa el tinte ictérico de la piel es un síntoma del principio, mientras que en nuestra epidemia, élla se ha presentado en el tercero o cuarto día de la enfermedad; la albuminuria en la remitente biliosa es muy rara y poco marcada, en tanto que en la epidernia de Piura ésta ha sido bien marcada desde el primer día, la mayoría de las veces, y se ha ido acentuando a medida que iba progresando la enfermedad; la temperatura en la remitente biliosa se mantiene elevada muchos días, mientras que en la epidemia que estamos describiendo ella ha caído al tercer o cuarto día de la enfermedad; el pulso en el paludismo no es tan marcadamente lento como el de la fiebre amarilla y, por último, apesar de la gran cantidad de veces que buscamos el hematozoario en la sangre de los enfermos-más de 300 observaciones-nunca pudimos encontrarlo, mientras que en las diversas formas de paludismo se encuetra casi siempre y con relativa facilidad.

Icteria infecciosa hemorrágica o enfermedad de Weil. - La leptospirosis ícterohemorrágica es una de las enfermedades que presenta mayores analogías, tanto clínicas como anatomopatológicas, con la fiebre amarilla, pero las condiciones epidemiológicas, entre las que podíamos citar la importancia que desempeñan las ratas en la diseminación de la leptospirosis ictero-hemorrágica, según los trabajos de INADA é lDo en el Japón, confirmados por los sabios franceses COURMont y DURAND, quienes han demostrado, en Lyon; que la rata de albañal es un reservorio del virus, asi como la preferencia de desarrollarse dicha leptospirosis a continuación de las lluvias que enlodan el suelo, principalmente entre los trabajadores de minas húmedas, permiten diferenciarla de nuestra epidemia de Piura, pues en la difusión de ésta no han desempeñado rol importante las ratas, sino los zancudos Stegomias, quienes se procrean en el agua de bebida y no tienen nada que ver con los pantanos y aguas estancadas, como pasa en la leptospirosis de INADA, IDo,etc. Esto por un lado. Por otro, tenemos la duración y marcha de la enfermedad, así como la temperatura, que son algo diferentes a las de la fiebre amarilla, pués en la leptospirosis la temperatura 
desciende epor-lisis y termina entre el décimo y décimo cuarto díc, siendo seguida, casi siempre, de temperaturas subnormales por espacio de tres o cuatro días, pudiendo ocurrir también una recaída febril, violenta, con reaparición de los síntomas del ataque inicial y recrudescencia de la icteria", (Julian ARCE.-Espiroquetosis ictero hemorrágica.- «La Crónica Médica Octubre 1917), cosa que no ha sucedido en la epidemia de Piura. En ninguno de nuestros casos, hemos podido descubrir temperaturas subnormales después de haber caído la fiebre, según lo acreditan nuestras historias clínicas; siempre esta temperatura se ha mantenido elevada durante los primeros días, para caer en el tercer o cuarto día de la enfermedad a 38 o 37, $1 / 2$ y persistir durante todo el curso de la enfermedad.

Por último, si el diagnóstico clínico es sumamente difícil hay que apelar al diagnóstico microbiológico para determinar la verdädera causa del proceso morboso, es decir, investigar la leptospira icterohemorragica, de INADA, IDO.

Fiebre y vomitos negros de los niños. - La fièbre amarilla y los vómitos negros de los niños presentan analogías clínicas, pero se pueden señalar diferencias que sirven para separarlos; asi, los vómitos négros es una endemia localizada en ciertas localidades, se maniesta en los niños de raza colorada y las recidivas frecuentes constituyen uno de sus caracteres particulares, contrariamente a lo que se observa en la fiebre amarilla. La icetria es fugaz y no se manifiesta nunca después de la muerte; además, puede evolucionar sin fiebre, lo que no pasa en la fiebre amarilla.

Demografía por Fiebre Amarilla en la ciudad de PiURa en 1919

Según la estadística la mortalidad media habida en Piura durante los primeros meses de la epidemia, ha sido de $32,5 \%$; esta cifra se descompone de la siguiente manera según los meses: 


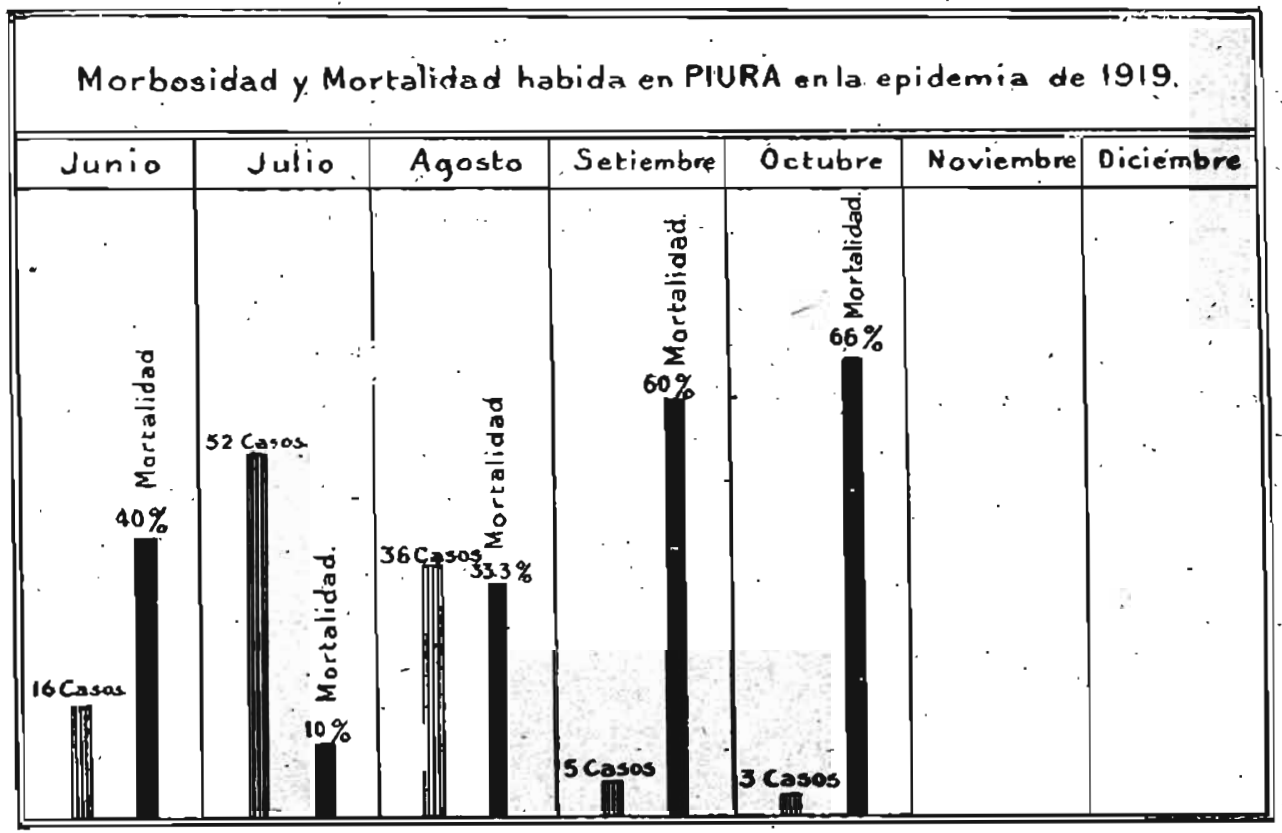

Total de casos 112.-Curados 79.-Muertos 33.-Mortalidad 32,5\%.

Según la procedencia, la edad y el sexo, el número total de enfermos se descompone así:

Del-Departamento de Piura: 91.

De otros departamentos: 21. Total: 112

Mayores de 30 años: 18.

Menores de 30 años: $94 . \quad$ Total : 112

Mujeres: 40 .

Hombres: $72 . \quad$ Total: 112

Desde el punto de vista de la procedencia, el número de fallecidos se descompone así:

Muertos de la sierra de Piura y otros lugares: 20 .

Muertos de la costa de Piura y otros lugares: 13. 
Como se vé la cifra de mortalidad de 32 ○ $33 \%$ habida en Piura, no es muy elevada, puesto que en esta apreciación nosotros tenemos en cuenta el hecho de que se trata sólo de casos netamente confirmados, ya que es muy probable, que en los primeros días en que apareció la epidemia en el departamento, un gran número de casos ligeros hayan escapado a nuestra observación, y si tuvieramos en cuenta todos estos casos, el porcentaje real de la mortálidad sería menos elevada, $y$ entonces podríamos adoptar las conclusiones formuladas por SIMOND, AUbER y Noc, a saber : "que la fiebre amarilla reviste formas ligeras, mucho más frecuente, que las. formas graves y que estas manifestaciones benignas pueden presentar todos los grados hasta simular una indisposición insignificante». Esta conclusión es perfectamente aplicable a la epidemia de Piura en los meses de Junio a Octubre de 1919, pues los casos benignos han predominado, y esto explica también porque los primeros pasaron desapercibidos no siendo descubierta dicha epidemia, hasta que no se presentaron los primeros casos fatales en los esposos Baca, que fallecieron con un intervalo de 40 horas; la muerte de éstos marca la aparición de la fiebre amarilla en Piura.

En esta epidemia han pagado mayor tributo los no aclimatados, tanto los de la sierra de este lugar (Piura), como los de la sierra de otros lugares del país', así como también los extranjeros.

También he hecho una separación entre los mayores de 30 años y de los menores de 30 , para conocer cuales han sido los mas atacados, hecho que estaría de acuerdo con los informes que he recogido, en el sentido de que hace ese número de años no se había presentado en Piura esta enfermedad, habiendo sido el año de 1890 el último, en que se presentó epidémicamente.

\section{CONCLUSIONES}

la.--La epidemia que há reinado y reina en el Departamento de Piura ha sido importada de la ciudad de Guayaquil.

2a.-Ella penetró por Tumbes, desde principios de Diciembre de 1918, traída por un agente viajero.

3a.--De esta ciudad se extendió a los centros petrolíferos de Talara y Negritos, en los meses de Marzo y Abril de 1919.

4a.-En el mesde Abril del mismo año, falleció en Paita una enferma que antes había estado en Tumbes y Talara, presentando sintomatología idéntica a los casos observados en las anterio res poblaciones. 
5a--Posteriormente, Mayo de 1919, fué denunciado en Colán y. Amotape una epidemia de idénticos caracteres que las anteriores. Dichos pueblos están situados en la inmediaciones del ferrocarril de Paita a Piura.

6a.-En los primeros días de Junio de dicho año, se presentó en la ciudad de Piura; la y'a mencionada epidemia con caracteres alarmantes, pues los dos primeros casos fallecieron en el intervalo de 40 horas.

7a.-Los datos epidemiológicos, la clínica, asi como las lesiones anatomopatológicas sacadas de los casos presentados subsiguientemente, nos hizo pensar que dicha epidemia era de "Fiebre stmarilla".

8a.--La campaña profiláctica que, desde entonces, se inició contra esta epidemia, bajo la dirección de profesionales del país, se ha coronado con brillante éxito.

9a.--La mortalidad habida en Piura ha sido de 32,5\%.

10a.--La campaña profiláctica, iniciada en Piura, se ha hecho según las leyes epidemiológicas, sentadas por las comisiones americana y francesa, que trabajaron en Cuba y Brasil respectivamente.

Mayo de 1920. 